\title{
Condition of Web Accessibility in Practice and Suggestions for Its Improvement
}

\author{
Tanja Krunić and Ljiljana Ružić-Dimitrijević, \\ The Advanced Technical School, Novi Sad, Serbia
}

\author{
krunic@nspoint.net ljaga@eunet.yu
}

\begin{abstract}
With the current development of the Internet and its growing use it is necessary to satisfy the needs of all users including those with disabilities causing accessibility problems. The paper deals with these categories of users and how much web designers take care of their abilities to access web locations they create. The $\mathrm{W} 3 \mathrm{C}$ organization has created a list of checkpoints regarding accessibility, which should be fulfilled by each website. A priority level representing a measure of improvement in accessibility is assigned to every checkpoint. Accordingly the authors of the paper have conducted a research of 200 web locations from different countries and obtained disturbing results on the presence of the basic accessibility principles in practice. In addition the paper offers a strategy for improving web accessibility in practice. Future web designers and managers ordering websites should be taught about the importance of web locations accessibility.
\end{abstract}

Keywords: accessibility, website, checkpoint, web design, user.

\section{Introduction}

The invention of the Internet can be compared with Gutenberg's press from the $15^{\text {th }}$ century as one of the greatest inventions of its time. Besides electronic books and magazines it is used to satisfy various needs in informing people, entertainment, communication, e-business, e-shopping, etc.

In today's fast way of life the Internet is becoming a necessity since a lot of obligations can be fulfilled over it. Web designers in cooperation with company managements are trying to make web presentations look as attractive as possible to their customers, so the goods and services offered are presented in the best light. Web pages dealing with e-commerce display catalogs with company products enabling users to order items from various assortments from their home or office.

How much are the needs and problems of customers taken into consideration during that process? Do all potential customers use the Internet easily and simply? Are there any user groups having

Material published as part of this publication, either on-line or in print, is copyrighted by the Informing Science Institute. Permission to make digital or paper copy of part or all of these works for personal or classroom use is granted without fee provided that the copies are not made or distributed for profit or commercial advantage AND that copies 1) bear this notice in full and 2) give the full citation on the first page. It is permissible to abstract these works so long as credit is given. To copy in all other cases or to republish or to post on a server or to redistribute to lists requires specific permission and payment of a fee. Contact Publisher@InformingScience.org to request redistribution permission. difficulties in accessing the Web, who on the other hand have an increased need to use it?

Web designers should follow the basic principles of design including correctness, usability, accessibility, user oriented web design, privacy, security, etc. All these principles should be built into websites, but it should also be pointed out that without accessibility numerous 
users cannot even feel any benefits of the remaining rules that have been applied. Therefore, a special attention must be paid to accessibility, which is the topic of this paper.

\section{Web Accessibility}

The World Wide Web Consortium (W3C) defines a website as accessible if it allows access to people with some kind of disability (W3C, 2005). Also we can find in the Wikipedia that accessible website involves "direct access" to all people (whether they have a disability or not). There is a strong relationship between accessibility and universal design (Wikipedia, n.d.). To realize the importance of web accessibility, let us consider the following statistical facts:

According to (The EU's Human rights \& Democratization Policy, 2004), disabled people are estimated to make up $10 \%$ of the world's population. In "Accessibility: Introduction to web accessibility" (2004), this number rises up to $20 \%$, or one fifth of the world's population. More than $5 \%$ of the EU citizens consider themselves as a disabled person, ("Attitude of Europeans towards disabilities," 2001). The same source claims that almost six of ten Europeans know someone who is affected by some kind of long lasting illness or disability. Similarly, a report (U.S. Census Bureau, 1997) categorizes $19.6 \%$ of the U.S. population as having some sort of disability. A detailed categorization of human disabilities influencing web design can be found in "Introduction to Web Accessibility" (Web Accessibility in Mind, 1998). We will mention only the main categories: the visually impaired (the blind, color blind), the deaf, mobility impaired (including temporarily impaired people, e.g. people with the broken wrist), and people with cognitive disabilities.

\section{Users Having Difficulties in Using the Web}

Creating accessible websites is not only important for users with some kind of disability. There is a long list of users having difficulties when searching the Web. Web Content Accessibility Guidelines 1.0, (1999), gives a list of people dealing with problems when accessing the web as they may function in circumstances very different from those of the typical user:

- People with disabilities (visual, hearing, mobility and cognitive disabilities)

- People having difficulties when reading or comprehending a text

- People who do not have or are not able to use a keyboard or a mouse

- Text only screen, small screen, or slow Internet connection owners

- People who do not speak or understand the language in which the document is

- People being in a situation where their eyes, ears, or hands are busy or interfered (e.g., driving, working in a noisy environment, etc.)

- People owning an early version of a browser, a totally different browser, a voice browser, or a different operating system.

Considering all these groups of web users together, we can see the real importance of accessible web design.

\section{Assistive Technologies}

Users with disabilities frequently rely on hardware and software to make web content accessible for them. These tools are known as assistive technologies. A list of various types of assistive technology products with brief descriptions, currently available in the market can be found in (Types of Assistive Technology Products, 2005). Only a few of the most common in use will be described herein. We will also stress what web designers should enable a successful use of these technologies. 
- A screen reader represents software used by blind users of the Web for reading the content of a web page out loud. For that purpose, it is essential to provide text descriptions for images and animations, because a screen reader can only read text. Such a text description of images and animations is called alternative text, or shortly, 'alt' text.

- A touch screen helps a mobility impaired individual to navigate a web page using his/her hands without the fine motor control required by the mouse. For the use of touch screens it is very important that the components of the page are designed to work without using the mouse. For example, dropdown menus and rollovers should have keyboard shortcuts.

- A head pointer helps a mobility impaired individual to interact with a keyboard or a touch screen. It is a stick placed in the user's mouth or mounted on a head strap. To be available the elements of the page are to be designed to work without using the mouse.

\section{Web Content Accessibility Guidelines 1.0}

The Web Content Accessibility Guidelines (1999) were created by the W3C aiming to explain to web designers how to make the web content accessible for people with disabilities. In addition, the application of these guidelines makes the web content more available for all users, whatever user agent they use (desktop browser, voice browser, mobile phone, automobile-based personal computer). It also helps people searching the Web under extraordinary circumstances like working in a noisy environment, under- or over- illuminated room, or with one's hands free, etc. The acceptance of these guidelines will also enable typical users to find information on the Web more quickly.

The document includes fourteen guidelines, or general principles of accessible web design. Each guideline includes a statement and an explanation. For the sake of simplicity, we will present only the statements of each guideline (typed in bold) and a brief description. The complete explanation of each guideline can be found in the original document. The accessibility guidelines are the following:

1. Provide equivalent alternatives to auditory and visual content. Provide content (text equivalents) that, when presented to the user, conveys essentially the same function or purpose as auditory or visual content. Text equivalents for auditory and visual content can be rendered in ways that are accessible to people from various disability groups using a variety of assistive technologies.

2. Don't rely on color alone. Ensure that text and graphics are understandable when viewed without color. In contrary, people who cannot differ certain colors and users with devices that have non-color or non-visual displays will not receive the information. When foreground and background colors are too close to the same hue, they may not provide sufficient contrast when viewed using monochrome displays or by people with different types of color deficits.

3. Use markup and style sheets and do so properly. Misusing markup for a presentation effect (e.g., using a table for layout or a header to change the font size) makes it difficult for users with specialized software to understand the organization of the page.

4. Clarify natural language usage. Use markup that facilitates pronunciation or interpretation of abbreviated or foreign text. When content developers mark up natural language changes in a document, assistive technologies can automatically switch to the new language.

5. Create tables that transform gracefully. Ensure that tables have necessary markup to be transformed by accessible browsers and other user agents. Tables should only be used 
to mark up truly tabular information, but not to lay out pages because that causes special problems to users of screen readers.

6. Ensure that pages featuring new technologies transform gracefully. Ensure that pages are accessible even when newer technologies are not supported or are turned off.

7. Ensure user control of time-sensitive content change. Ensure that moving, blinking, scrolling, or auto-updating objects or pages may be paused or stopped. People with cognitive or visual disabilities are unable to read moving text. Screen readers are unable to read moving text.

8. Ensure direct accessibility of embedded user interfaces. Ensure that the user interface provides device-independent access to functionality, keyboard operability, self-voicing, etc. When an embedded object has its "own interface", it must be accessible. If such an interface cannot be made accessible, an alternative accessible solution must be provided.

9. Design for device-independence. Use features that enable activation of page elements via a variety of input devices.

10. Use interim solutions. This will help assistive technologies and older browsers to operate correctly. For example, older browsers do not allow navigating to empty edit boxes. It is also advisable to avoid changing the current window or popping up new windows, because this confuses blind users.

11. Use W3C technologies and guidelines. The current guidelines recommended W3C technologies (HTML, CSS, etc.) include "built-in" accessibility features. On the other hand, non W3C formats (Shockwave, PDF, etc.) require viewing with either plug-ins or stand-alone applications. Often, these formats cannot be viewed or navigated with standard user agents (including assistive technologies).

12. Provide context and orientation information. Grouping elements and providing contextual information about the relationships between elements is useful for all users. On the other hand, complex relationships between parts of a page may be difficult for people with cognitive disabilities and people with visual disabilities to interpret.

13. Provide clear navigation mechanisms. Provide clear and consistent navigation mechanisms (orientation information, navigation bars, site maps, etc.). This is very important for the orientation of people with cognitive disabilities or blindness, and benefits all users.

14. Ensure that documents are clear and simple. Consistent page layout, recognizable graphics, and easy to understand language benefit all users, but especially people with cognitive disabilities and people whose first language differs from your own.

In addition, every guideline is followed by an appropriate list of checkpoint definitions. The checkpoint definitions in each guideline explain how the guideline is applied in typical content development scenarios. Each checkpoint is intended to be specific enough so that any web page reviewer may verify whether it is satisfied or not. The paper does not present all the checkpoints since they can be found in the original document or in Checklist of Checkpoints for Web Content Accessibility Guidelines 1.0 (1999).

Moreover, each checkpoint has a priority level based on the checkpoint's impact on accessibility. Let us introduce these levels:

- Priority 1. A web content developer must satisfy this checkpoint. Otherwise, it will be impossible for several groups of users to access information in the document. Satisfying 
this checkpoint is the basic requirement for the ability of some user groups to use web documents.

- Priority 2. A web content developer should satisfy this checkpoint. Otherwise, for several groups of users it will be difficult to access information in the document. Satisfying this checkpoint removes significant barriers to accessing web documents.

- Priority 3. A web content developer should address this checkpoint. Otherwise, several groups of users could find it somewhat difficult to access information in the document. Satisfying this checkpoint improves access to web documents.

We must mention that some checkpoints specify a priority level that may change under certain (indicated) conditions.

W3C also defines tree levels of conformance to the WCAG:

- Conformance Level "A": all Priority 1 checkpoints are satisfied;

- Conformance Level "Double-A": all Priority 1 and 2 checkpoints are satisfied;

- Conformance Level "Triple-A": all Priority 1, 2 and 3 checkpoints are satisfied;

Conformance levels are spelled out in text so they may be understood when rendered to speech.

To further promote accessibility on the Web, the W3C has introduced the WCAG Conformance logos, Figure 1. Web content developers can use them on their sites to indicate a claim of conformance to a specified conformance level of the WCAG. The Conformance logos are also called WCAG-icons and are available at WCAG-ICONS (2006).
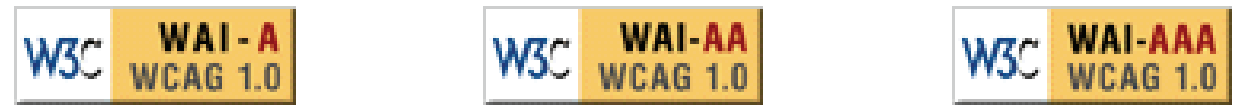

Figure 1: WCAG Conformance logos

It is upon web content developers to decide which of the three levels of conformance to claim for their web page. Then they can claim conformance of their page with the WCAG using the appropriate WCAG-icon, or inserting the following text into their page:

“This page conforms to W3C's 'Web Content Accessibility Guidelines 1.0' available at http://www.w3.org/TR/1999/WAI-WEBContent-19990505, level” (specify the level).

Content providers are solely responsible for the use of the conformance logos. Therefore, before the use of these logos, it is recommendable that the provider becomes familiar with the WCAG and use a variety of review methods to ensure that any page using the appropriate logo meets the conformance level claimed.

\section{National Accessibility Standards}

In specific countries, national standards emerged after the creation of the WCAG by the W3C. Section 508 of the Federal Rehabilitation Act in the U.S. is based on WCAG Priority 1 (Section 508, 2006). Common Look and Feel in Canada (Adaptive Computer Technology Training Center, 1999) and Web Guidelines (e-Government Unit, 2005) in the United Kingdom are based on Priorities 1 and 2 from the WCAG. The W3C provides an extensive listing of national standards initiatives. Unfortunately, all these national standards do not directly apply to the private sector. 


\section{Accessibility Validation}

The accessibility of a web page can be validated with automatic tools and human reviewing. Automated methods are generally rapid and convenient but cannot identify all accessibility issues. For example, an automated validation method can check if an image is followed with 'alt' text, but it cannot realize if the text is an appropriate explanation of the given image or not. On the other hand, the human review is very slow, but it can help ensure some issues like clarity of language and ease of navigation. Let us introduce in short some validation methods. A more detailed discussion can be found in Chisholm, Vanderheiden, and Jacobs (2000).

Validation methods:

1. Use an automated accessibility tool and browser validation tool. You can found a list of automated checking tools and their descriptions in Foley and Regan (2005). We will mention only WebEXACT, since it is a free on-line web content accessibility checking tool available at http://webxact.watchfire.com/. WebEXACT returns the page with a report of obvious accessibility difficulties on the page. Also, the following free on-line checking tools can be used:

Truwex Online 2.0 beta $<\underline{\text { http://checkwebsite.erigami.com/accessibility.html }}>$, WAVE 3.5 Accessibility Tool < http://www.wave.webaim.org/wave35/index.jsp $>$, Cynthia Says ${ }^{\mathrm{TM}}$, Torquemada $<\underline{\text { http: } / / \text { www.webxtutti.it/testa en.htm }}>$, TAW Online, $<$ http://www.tawdis.net/taw3/cms/es $>$ and AskAlice $<$ http://askalice.ssbtechnologies.com:8080/ssb/aa/anon/index.jsp $>$.

2. Validate syntax (e.g. use HTML\&XHTML - validator, 2006 http://validator.w3.org ).

3. Validate style sheets (e.g. use CSS - validator, 2004 http://jigsaw.w3.org/css-validator ).

4. Use a text only browser or emulator.

5. Use a multiple graphic browser simulating the following situations: sounds and graphics loaded, graphics not loaded, sound not loaded, no mouse, frames, scripts, style sheets and applets not loaded.

6. Check the page in several browsers, old and new.

7. Use some available assistive technologies (e.g. screen reader)

8. Use spell and grammar checkers

9. Review the document for clarity and simplicity

10. Let people with different types of disabilities review the document.

\section{Reasons for Accessible Design}

Let us briefly explain the main reasons for accessible web design introduced by Foley and Regan (2005).

- Accessibility opens doors to information for individuals with disabilities. It supports the independence of disabled individuals helping them to participate in day-to-day activities like on-line shopping, entertainment, reading news, etc.

- It is obligatory for national institutions in several countries.

- Accessibility offers benefits for all users by creating more usable sites. 
- Accessible web design is based on more contemporary architecture and design that allow a greater flexibility across a site.

- Together with the web accessibility increase, there is a rise of interest for assistive technologies. Hence, accessibility represents a growing market in need of software, hardware and design.

\section{Economic Benefits for Companies Creating Accessible Websites}

This paper is particularly focused on the accessibility of websites representing e-commerce, (online stores, advertising websites, etc.) since they help people with disabilities to make an effort toward their independence. On the other hand, as mentioned before, there are no obligations for the private sector imposed by national governments regarding accessible design.

Since accessible web design requires some additional costs, there is always a question for the company management whether the creating of an accessible on-line store brings benefits to the company, or perhaps it is just a waste of time and money.

Let us explain some of the additional costs for creating an accessible website.

- The website has to be tested in several browsers (old and new).

- The website has to be reviewed using different kinds of assistive technologies.

- Manual reviewing of the website accessibility is time consuming. So it takes time before the website appears online, and this means a loss of profit.

- A more qualified web designer has to be hired for creating the website.

However, in our opinion, there are three main advantages in accessible web design that bring profit to companies.

- There is a significant increase of the number of customers, since accessible design makes the website available to a wider circle of people. People with disabilities and others having problems searching the Web have access to company on-line stores, or are able to read the company products advertisements.

- An accessible website is easier to browse for all users. Consequently, the company website will have a large number of satisfied visitors.

- The company reputation increases due to the social care for people with disabilities.

Finally, if we compare the cost for accessible design on one side, and the benefits on the other (Figure 2), we can conclude the following: companies benefit from accessible web design.

\section{Website Accessibility Analysis}

One might conclude that disabled people have no problems any more while surfing through the Internet, since there is a strong web accessibility support through the $\mathrm{W} 3 \mathrm{C}$ web accessibility guidelines and a growing market of assistive technologies.

The goal of this paper is to find out if web accessibility is respected in practice, or not. A short web accessibility analysis previously presented in (Krunic, Ruzic-Dimitrijevic, Petrovic, \& Farkas, 2006) was disappointing. Namely, the accessibility of 50 arbitrarily chosen websites around the world was tested by using WebEXACT, the free online service for testing accessibility of web content (http://webxact.watchfire.com/). Only 34\% of the tested pages satisfied Priority 1 checkpoints meaning that almost $66 \%$ of the disabled people have no access to these pages. The number of web pages satisfying Priority 2 and 3 checkpoints were even lower (Priority $2-0 \%$, Prior- 


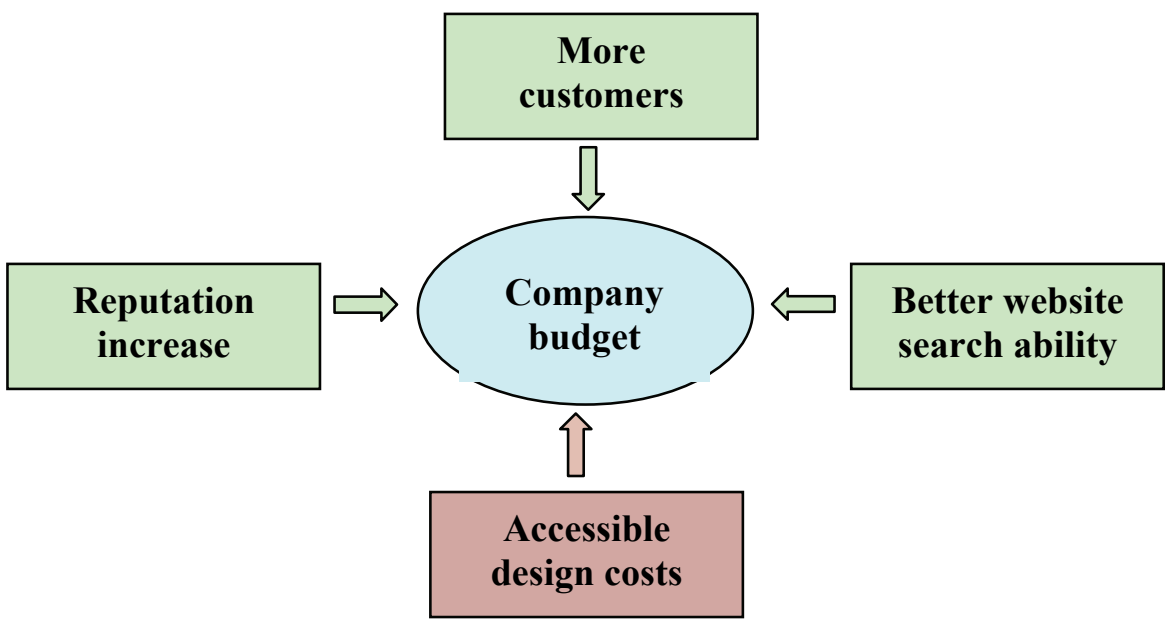

Figure 2: Economic benefits for companies to create accessible website

ity 3 only $6 \%$ ). Performing the test, the authors realized that the values decreased with every newly tested web page.

Since the results of the test indicated that the situation with web accessibility is quite unsatisfactory in practice, the idea was to widen the analysis and find out the most recent errors against web accessibility. The first step in that direction was made in (Krunic, 2006). The paper presents a detailed analysis of errors related to Priority checkpoints 1-3 in 30 websites in Serbia. The error analysis points to the lack of text equivalents for non-text elements (images, graphical representations of text, image map regions, animations, etc.) as the most frequent error against accessibility checkpoints of Priority 1. Checkpoints of Priority 2 are not completely satisfied due to the use of absolute units in markup language attribute values and style sheet property values, associate labels not explicitly associated with their controls and lack of a clear identification of the target of each link. Checkpoints of Priority 3 are violated due to the lack of identification of the primary natural language of a document, absence of summaries for tables, the lack of non-link, printable characters (surrounded by spaces) between adjacent links and default, place-holding characters in edit boxes and text areas.

So we have two interesting questions: What happens if we widen the small sample of tested websites, and is the situation similar worldwide, or we have completely different errors against accessibility from country to country? Answers to these questions would be a major effort in supporting web accessibility in practice, since the most recent errors regarding web accessibility would we identified. Their identification would further serve as an additional short guideline in educating web designers. A special attention should be paid to this when creating websites in order to improve accessibility. Focusing on only several accessibility guidelines could be more effective, since a long list of guidelines usually results in ignoring them all.

\section{Research Methodology}

For the purpose of this paper, 200 websites from 12 different countries (the list can be found in the Appendix) mainly dealing with e-commerce were tested. This choice was made since on-line shopping is an activity which can improve the life quality of the disabled - as it supports their independence from other people's help. Again we used the free online service for testing web content accessibility WebEXACT. But this time, along with a number of websites satisfying all 
checkpoints of Priority 1-3, we also observed errors against accessibility which are included in the WebEXACT scanning report.

This research was conducted by students as a project at the course Introduction to Web Design. They used some of search engines searching for web locations containing the phrase "online shopping + name of country", or similar. The choice of countries was arbitrarily. From the obtained WebEXACT report they entered data about their satisfying all checkpoints of Priority 1-3 (Table 1 and Figure 3) as well as checkpoint numbers of every priority dissatisfied (Tables 2, 3, 4, 5 and Figures 4, 5). Types of errors were counted for each location and then their occurrence in percentages was calculated.

Since all listed validators give more or less the same values only one of them was presented to the students during exercises, therefore, they used the same validator.

\section{Research Results}

Table 1 proves the low accessibility of websites in practice, since it shows that $84 \%$ of websites are completely inaccessible to disabled people. In comparison to the results of the test performed in (Krunic et al., 2006), the accessibility situation obtained herein is even worse. This fact agrees with our conclusion that the number of accessible websites decreases with every additional web page tested.

Table 1: Results of the web accessibility test

\begin{tabular}{|l|c|c|c|}
\cline { 2 - 4 } \multicolumn{1}{c|}{} & Priority 1 & Priority 2 & Priority 3 \\
\hline $\begin{array}{l}\text { Number of websites satisfying all checkpoints of } \\
\text { the appropriate priority }\end{array}$ & 32 & 2 & 2 \\
\hline Percentage & $16 \%$ & $1 \%$ & $1 \%$ \\
\hline
\end{tabular}

Figure 3 shows that the low website accessibility is present in all tested countries. Since the countries were arbitrarily chosen, we can conclude there is a global deficiency of web accessibility in practice.

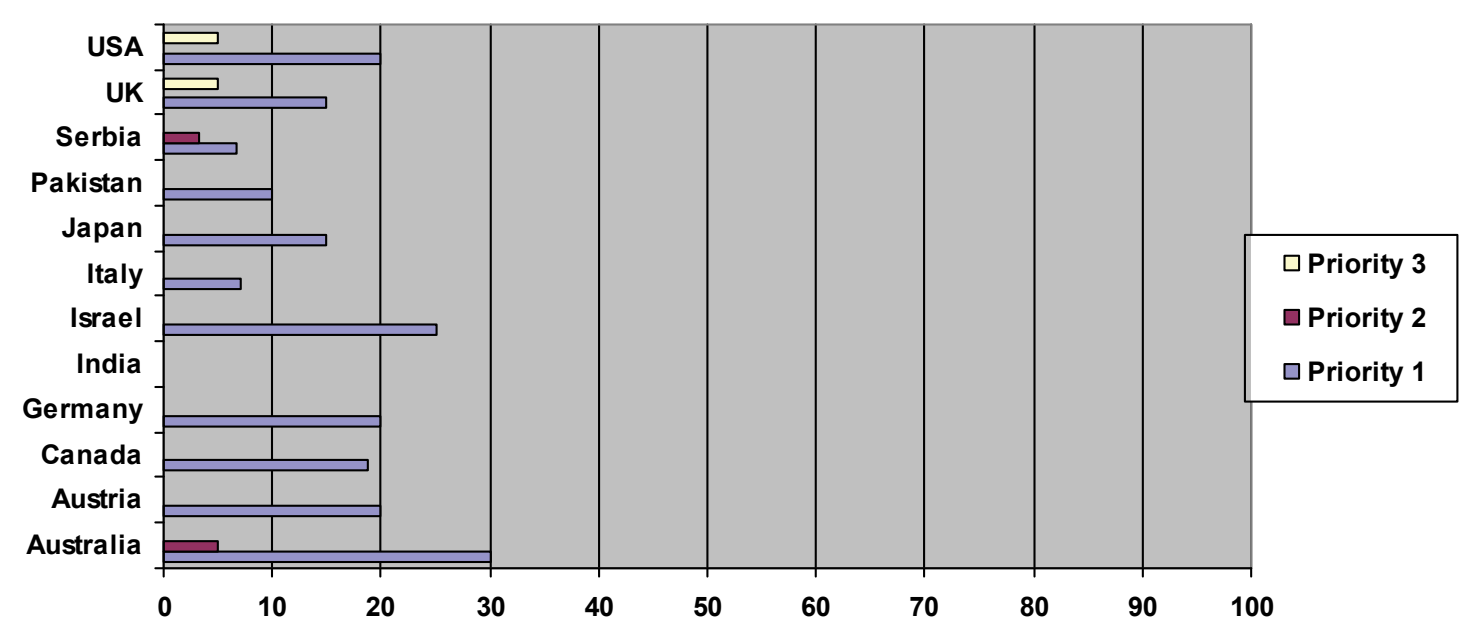

Figure 3: Percentage of web sites satisfying Checkpoints of Priority 1-3 
Let us now consider the errors against web accessibility found in the WebEXACT report checklist (Tables 2-4). We will only present checkpoints of the appropriate Priority which were not fulfilled in the tested websites. The complete list of checkpoints of Priorities 1-3 can be found in Checklist of Checkpoints for Web Content Accessibility Guidelines 1.0 (1999).

Table 2: Percentage of websites with checkpoint errors of Priority 1

\begin{tabular}{|l|c|c|}
\hline \multicolumn{1}{|c|}{ Priority 1 checkpoints } & $\begin{array}{c}\text { Number of websites not } \\
\text { satisfying the appropriate } \\
\text { checkpoint }\end{array}$ & Percentage \\
\hline $\begin{array}{l}\text { 1.1 Provide alternative text for all images. Provide alter- } \\
\text { native text for all images map hot-spot (Areas). }\end{array}$ & 166 & $83 \%$ \\
\hline 6.2 Each FRAME must refer to an HTML file & 6 & $3 \%$ \\
\hline 12.1 Give each frame a title. & 26 & $13 \%$ \\
\hline $\begin{array}{l}12.4 \text { Provide alternative text for all image-type buttons } \\
\text { in forms. }\end{array}$ & 45 & $22.5 \%$ \\
\hline
\end{tabular}

As we can see from Table 2, the reason for violating Priority 1 is mainly ( $83 \%)$ caused by not providing alternative text for images.

Table 3: Percentage of websites with checkpoint errors of Priority 2

\begin{tabular}{|c|c|c|}
\hline Priority 2 checkpoints & $\begin{array}{l}\text { Number of websites not } \\
\text { satisfying the appropriate } \\
\text { checkpoint }\end{array}$ & Percentage \\
\hline $\begin{array}{l}\text { 3.2 Use a public text identifier in a DOCTYPE state- } \\
\text { ment. }\end{array}$ & 85 & $42,5 \%$ \\
\hline $\begin{array}{l}3.4 \text { Use relative sizing and positioning, rather than } \\
\text { absolute }\end{array}$ & 181 & $90,5 \%$ \\
\hline 3.5 Nest headings properly. & 9 & $4,5 \%$ \\
\hline $\begin{array}{l}6.5 \text { Ensure that dynamic content is accessible or pro- } \\
\text { vide an alternative presentation or page }\end{array}$ & 1 & $0,5 \%$ \\
\hline $\begin{array}{l}7.3 \text { Avoid scrolling text created with the MARQUEE } \\
\text { element. }\end{array}$ & 5 & $2,5 \%$ \\
\hline 7.4 Do not make a page refresh automatically & 2 & $1 \%$ \\
\hline 7.5 Do not make a page redirect to a new URL. & 1 & $0,5 \%$ \\
\hline $\begin{array}{l}\text { 9.3 Make sure event handlers do not require using the } \\
\text { mouse. }\end{array}$ & 107 & $53,5 \%$ \\
\hline $\begin{array}{l}\text { 10.1 Until user agents allow users to turn off spawned } \\
\text { windows, do not make pop-ups or other windows ap- } \\
\text { pear and do not change the current window without } \\
\text { informing the user. }\end{array}$ & 1 & $0.5 \%$ \\
\hline $\begin{array}{l}12.4 \text { Explicitly associate form controls and their labels } \\
\text { with the LABEL element. }\end{array}$ & 171 & $85,5 \%$ \\
\hline $\begin{array}{l}\text { 13.1 Create link phrases that make sense when read out } \\
\text { of context. Do not use the same link phrase more than } \\
\text { once when the links point to different URLs. }\end{array}$ & 176 & $88 \%$ \\
\hline 13.2 Include a document TITLE. & 1 & $0,5 \%$ \\
\hline
\end{tabular}


Table 3 indicates Priority 2 checkpoints 3.4, 12.4 and 13.1 are mainly ignored by web designers when creating a website.

From Table 4 we can see that violating Priority 3 Checkpoints usually happens due to not respecting guidelines 4.3, 5.5, 10.4 and 10.5. As we can see, the main errors against Priorities 1-3 found in the tested websites agree with those found for one country, i.e. Serbia (Krunic, 2006).

Table 4: Percentage of websites with checkpoint errors of Priority 3

\begin{tabular}{|l|c|c|}
\hline \multicolumn{1}{|c|}{ Priority 3 checkpoints } & $\begin{array}{c}\text { Number of websites not } \\
\text { satisfying the appropriate } \\
\text { checkpoint }\end{array}$ & Percentage \\
\hline $\begin{array}{l}\text { 1.5 Until user agents render text equivalents for client- } \\
\text { side image map links, provide redundant text links for } \\
\text { each active region of a client-side image map. }\end{array}$ & 32 & $16 \%$ \\
\hline $\begin{array}{l}\text { 4.3 Identify the primary natural language of a docu- } \\
\text { ment. }\end{array}$ & 174 & $87 \%$ \\
\hline $\begin{array}{l}\text { 5.5 Provide summaries for tables. } \\
\text { 10.4 Until user agents handle empty controls correctly, } \\
\text { include default, place-holding characters in edit boxes } \\
\text { and text areas. }\end{array}$ & 187 & $93,5 \%$ \\
\hline $\begin{array}{l}\text { 10.5 Until user agents (including assistive technolo- } \\
\text { gies) render adjacent links distinctly, include non-link, } \\
\text { printable characters (surrounded by spaces) between } \\
\text { adjacent links. }\end{array}$ & 159 & $79,5 \%$ \\
\hline
\end{tabular}

Moreover, we have a similar situation in all 12 tested countries, (Figures 4, 5 and Table 5). This indicates that there is a global problem of not respecting appropriate accessibility guidelines.

Table 5: Percentage of websites with Checkpoint Errors of Priority 2 for different countries

\begin{tabular}{|l|c|c|c|c|c|c|c|c|c|c|c|c|}
\hline & $\mathbf{3 . 2}$ & $\mathbf{3 . 4}$ & $\mathbf{3 . 5}$ & $\mathbf{6 . 5}$ & $\mathbf{7 . 3}$ & $\mathbf{7 . 4}$ & $\mathbf{7 . 5}$ & $\mathbf{9 . 3}$ & $\mathbf{1 0 . 1}$ & $\mathbf{1 2 . 4}$ & $\mathbf{1 3 . 1}$ & $\mathbf{1 3 . 2}$ \\
\hline USA & 45 & 95 & 0 & 0 & 0 & 95 & 0 & 65 & 0 & 90 & 95 & 0 \\
\hline UK & 25 & 80 & 0 & 0 & 5 & 0 & 0 & 70 & 0 & 90 & 95 & 0 \\
\hline Serbia & 46,67 & 93,33 & 6,67 & 3,33 & 3,33 & 3,33 & 0 & 40 & 3,33 & 86,67 & 73,33 & 0 \\
\hline Pakistan & 30 & 90 & 0 & 0 & 0 & 0 & 0 & 80 & 0 & 80 & 100 & 0 \\
\hline Japan & 50 & 90 & 0 & 0 & 0 & 0 & 0 & 50 & 0 & 90 & 95 & 0 \\
\hline Italy & 28,57 & 92,86 & 0 & 0 & 0 & 0 & 0 & 57,14 & 0 & 100 & 78,57 & 0 \\
\hline Israel & 40 & 90 & 25 & 0 & 0 & 5 & 0 & 40 & 0 & 85 & 80 & 0 \\
\hline India & 3,2 & 3,4 & 3,5 & 6,5 & 7,3 & 7,4 & 7,5 & 9,3 & 10,1 & 12,4 & 13,1 & 13,2 \\
\hline Germany & 70 & 90 & 0 & 0 & 10 & 0 & 0 & 40 & 0 & 60 & 80 & 0 \\
\hline Canada & 43,75 & 93,75 & 0 & 0 & 0 & 0 & 0 & 43,75 & 0 & 93,75 & 100 & 0 \\
\hline Austria & 40 & 100 & 00 & 0 & 10 & 0 & 0 & 50 & 0 & 100 & 90 & 10 \\
\hline Australia & 35 & 80 & 5 & 0 & 0 & 0 & 0 & 70 & 0 & 55 & 90 & 0 \\
\hline
\end{tabular}

In this case we used the table instead a figure with a graph because of the large number of checkpoint errors, which would produce too many colors in the figure. 


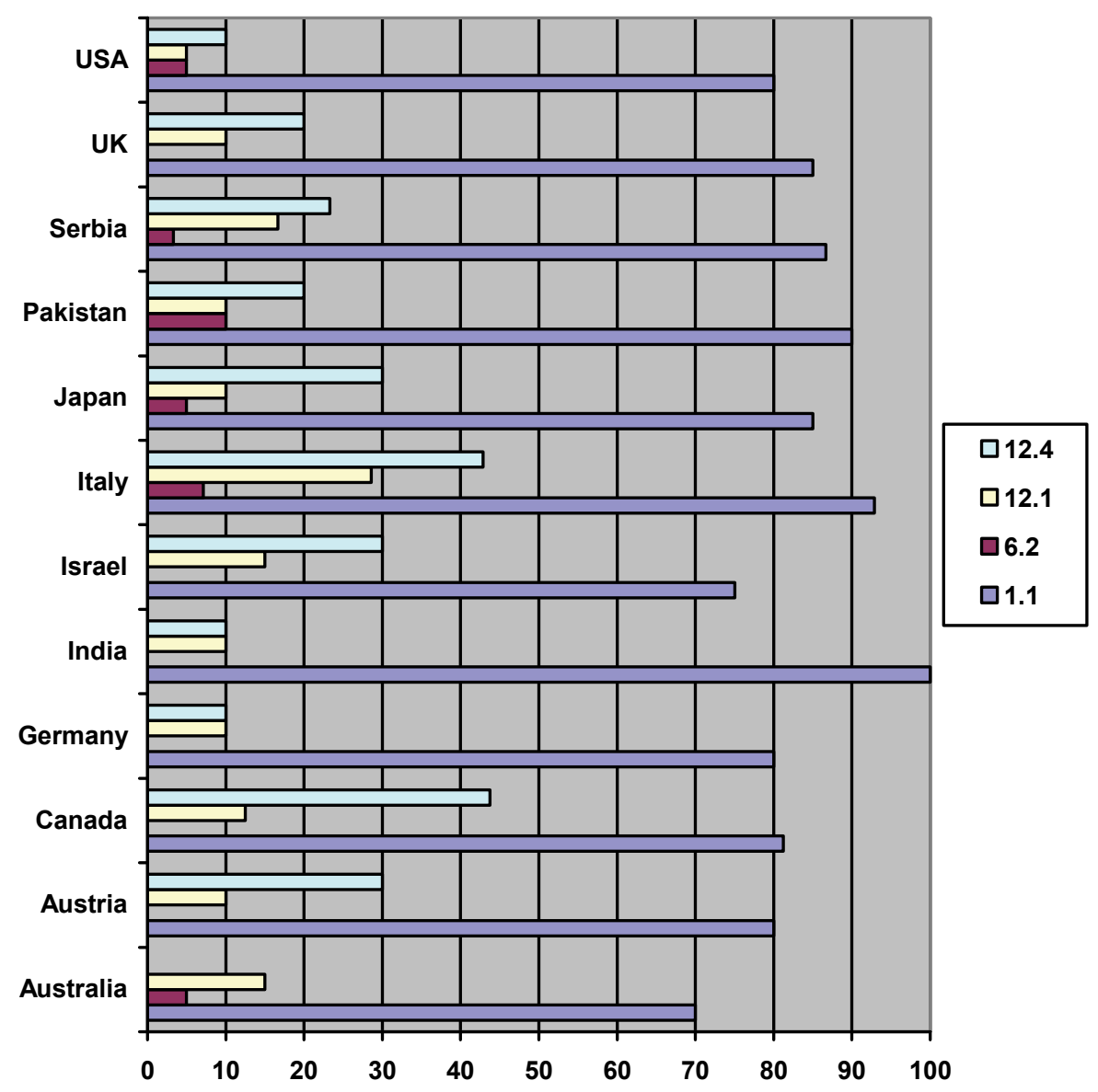

Figure 4: Percentage of websites with Checkpoint Errors of Priority 1 for different countries

\section{A Strategy for Improving Web Accessibility in Practice}

After analyzing the errors against accessibility found in the tested websites, we suggest the shortened list of accessibility checkpoints bellow. A special attention should be paid to it when teaching accessibility to future web designers, or when contracting a creation of a website. This is particularly important for the checkpoints of Priority 1, since satisfying the checkpoints of Priority 1 is the essential condition for people with disabilities to access information from a website.

\section{Priority 1 checkpoints:}

1.1 Provide alternative text for all images. Provide alternative text for all images map hot-spot (AREAs).

\section{Priority 2 checkpoints:}

3.4 Use relative sizing and positioning, rather than absolute.

12.4 Explicitly associate form controls and their labels with the LABEL element.

13.1 Create link phrases that make sense when read out of context. Do not use the same link phrase more than once when the links point to different URLs. 


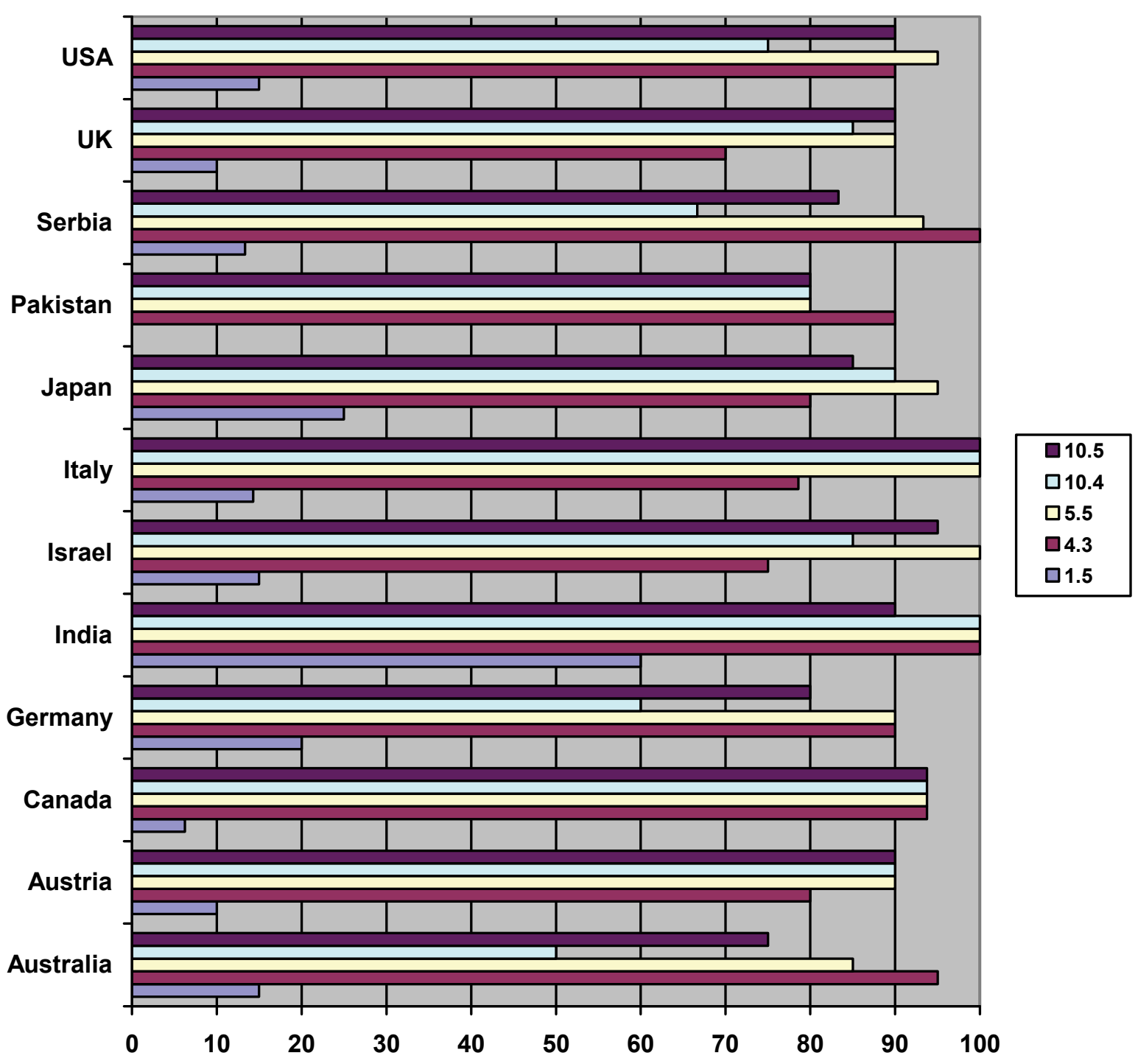

Figure 5: Percentage of websites with Checkpoint Errors of Priority 3 for different countries

\section{Priority 3 checkpoints:}

4.3 Identify the primary natural language of a document.

\subsection{Provide summaries for tables.}

10.4 Until user agents handle empty controls correctly, include default, place-holding characters in edit boxes and text areas.

10.5 Until user agents (including assistive technologies) render adjacent links distinctly, include non-link, printable characters (surrounded by spaces) between adjacent links.

Since this is a shorter list of checkpoints, it cannot serve to create a perfectly accessible website. But its shortness can help web designers to focus themselves on several points only, creating a relatively accessible website. This can be an effort in improving accessibility for, as mentioned 
before, the complete list of accessibility guidelines is long, and therefore, many web designers ignore them all.

In our opinion, it is of great importance to include at lest this shortened list of checkpoints as topics of HTML and similar web courses for study groups in web education. A much bigger effort in the sense of web accessibility would be to present to students the whole list of accessibility checkpoints (at least of Priority 1), paying a special attention to the shortened list of checkpoints, with an explanation that they present the most frequently violated checkpoints in practice. This would certainly be a good way for them to learn how to avoid the most common errors against accessibility.

However, web accessibility is a complex matter, so let us present our additional suggestion for the improvement of web accessibility:

Since web designers mainly ignore web accessibility, it is upon the educational system to inform them about its importance. Furthermore, the educational system (secondary and higher education) should provide future web designers with tools for creating accessible websites.

On the other hand, future managers, i.e. economy students should also be taught about the importance of web accessibility. This would help them to learn what exactly to request from the web designer regarding web accessibility when signing contracts for creating company websites. An additional duty of managers should be to inform customers about the accessibility of the company website, which could inspire disabled people to launch their own websites (Figure 6).

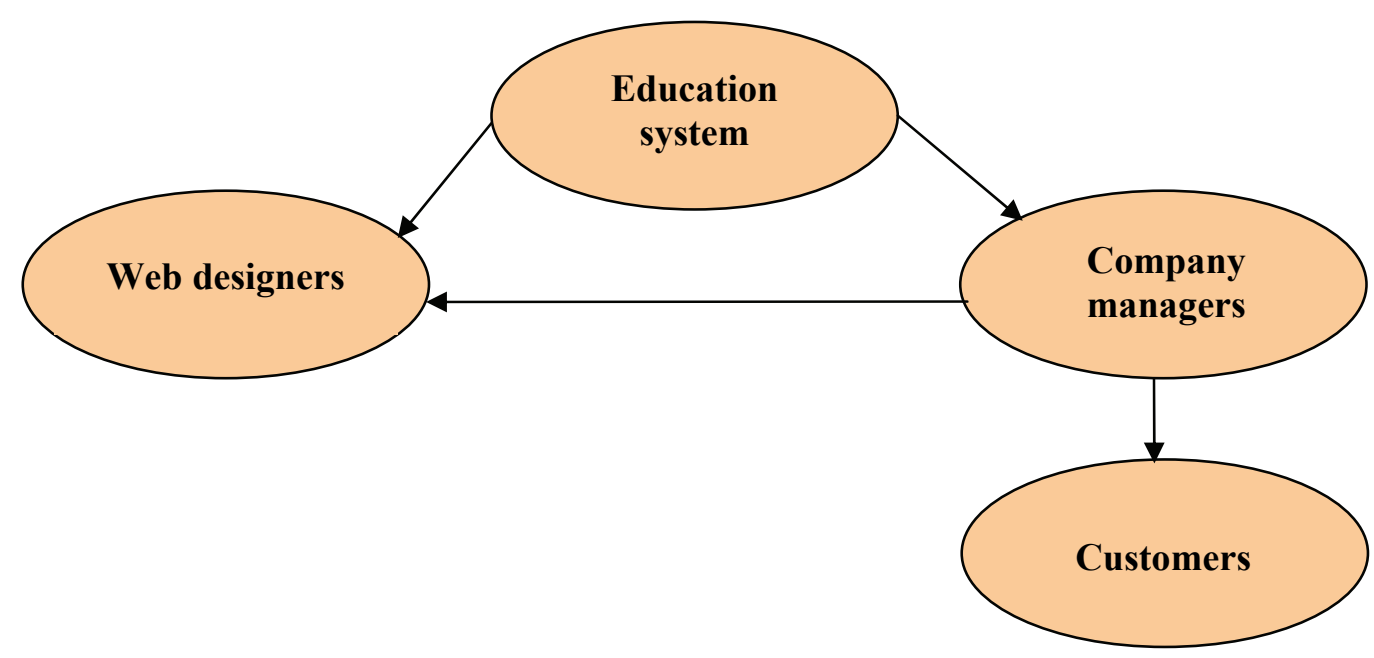

Figure 6: Organization chart for improving web accessibility through education

\section{Conclusion}

There is no doubt that designing websites accessible to all users is of great importance to every designer as well as to companies presenting themselves on the Internet. This importance reflects in an increased number of visits, and satisfaction of all users, particularly those who due to different reasons have difficulties with access. These users are the ones having an increased need to use the Internet in order to do various activities. Consequently, both the designers and companies that take care of accessibility increase profit, and their respect and rating in the market also grow. 
Why don't web designers take care of accessibility? One of the reasons is ad hoc designing because of a short time delivery. Web designers claim that they will take care of accessibility later, but it does not happen because of the pressure of the company owner to publish the website as soon as possible (Powell, 2000).

Therefore, it is necessary to educate designers and company managers about the importance of creating accessible websites. The education should be conducted according to the strategy mentioned in the previous chapter. In order to educate our web design students in that direction we are planning to organize courses on Internet usage for people with access difficulties that would be taught by the final year students. In this way they could realize the problems such Internet users deal with. Thus they would have a clear picture regarding the importance of usability, and an additional motive for creating adequate websites.

\section{References}

Accessibility: Introduction to web accessibility. (2004). California State University, Sacramento.

Adaptive Computer Technology Training Center. (1999). Retrieved March 3, 2003, from http://www.ec.gc.ca/act-tia/

Attitude of Europeans towards disability. (2001). Retrieved June 2006 from http://www.eu.nl/public_opinion/archives/ebs/ebs_149_summ_en.pdf

Checklist of checkpoints for web content accessibility guidelines 1.0. (1999). Retrieved March 2005 from http://www.w3.org/TR/WAI-WEBCONTENT/full-checklist.html

Chisholm, W., Vanderheiden, G., \& Jacobs, I. (2000). Techniques for web content accessibility guidelines 1.0. Available at http://www.w3.org/TR/WAI-WEBCONTENT-TECHS/

e-Government Unit, Delivery And Transformation Group. (2005). Web guidelines. Retrieved December 5, 2005, from http://www.cabinetoffice.gov.uk/e-government/resources/handbook/introduction.asp

The EU's Human rights \& Democratization Policy. (2004). Retrieved June 2006 from http://ec.europa.eu/comm/external_relations/human_rights/disability/index.htm.

Foley A., \& Regan, B. (2005). Best practices for web accessibility design and implementation. Retrieved March 2005 from www.kais-dso.eu.dodea.edu/technology/Resources/Webmasters/best practices.pdf

Krunic, T. (2006). Accessibility of e-commerce websites in Serbia and Montenegro. The 6th International Conference on Electronic Commerce and Electronic Business, Palic 2006.

Krunic, T, Ruzic-Dimitrijevic L., Petrovic, B., \& Farkas, R. (2006). Web design curriculum and syllabus based on web design practice and students' prior knowledge. Journal of Information Technology Education, 5(5), 317-335. Available at http://jite.org/documents/Vol5/v5p317-335Krunic153.pdf

Powell, T. A. (2000). Web design: The complete reference. MacGraw-Hill.

Section 508. (2006). Available at http://www.section508.gov/

Types of Assistive Technology Products. (2005). Retrieved June 2006 from http://www.microsoft.com/enable/at/types.aspx

U.S. Census Bureau. (1997). Americans with disabilities. Retrieved June 15, 2004 from http://www.census.gov/prod/2001pubs/p70-73.pdf

W3C. (2000). Curriculum for web content accessibility guidelines. Retrieved September 10, 2004 from http://www.w3.org/WAI/wcag-curric

W3C. (2005). What is web accessibility? Retrieved from http://www.w3.org/WAI/intro/accessibility.php

WCAG-ICONS, (2006). Information about conformance icons for the WCAG and how to use them. Available at http://www.w3.org/WAI/WCAG1-Conformace.html 
Web Accessibility in Mind (WebAIM). (1998). Introduction to Web accessibility. Retrieved April 23, 2004 from http://www.Webaim.org/info/intro

Web Content Accessibility Guidelines 1.0. (1999). Retrieved from http://www.w3.org/TR/1999/WAIWEBContent-19990505

Wikipedia. (n.d.). Accessibility. Retrieved November 14, 2006, from http://en.wikipedia.org/wiki/Accessibility

\section{Appendix}

\section{A List of Tested Sites}

\section{Australia:}

http://www.sunshinecomputers.com.au

http://www.about-australia.com

http://www.aussiebest.com

http:// www.aussie-shopping.com

http:// www.perfume.com.au

$\mathrm{http}: / /$ www.latestbuy.com.au

http://www.haabaa.com

http:// www.freestylemedia.com.au

http:// www.abc.com.au

http:// www.aboriginalaustralia.com

http://www.shopsafe.com.au

http://www.shoptheweb.com.au

http://www.coastshop.com.au

http://www.ozeworld.com

http://www.woolworths.com.au

http://www.umart.com.au

http://www.haabaa.com

http://www.scrapbookingtop50.com.au

http://www.bookworm.com.au

http://www.emailcash.com.au

\section{Austria:}

http://www.eplanetshopping.com/newfront/main.

asp

http://www.vienna.at

http://www.timeout.com/travel/vienna

https://ssl22.inode.at/shop.manova.at/catalog/

http://www.sony.com

http://www.freestylemedia.com.au/download.asp

http://shop.abc.net.au/help/viddvdinfo.shtm

http://www.ncbuy.com/travel/health/report_count ry.html? code $=$ au

http://www.dongabriel.net

http://www.vienna-hotels.inn26.com

\section{Canada:}

http://www.800florals.com

$\mathrm{http}: / / \mathrm{dmoz}$. org http://www.glacombe.com

http://www.infoedmonton.ca

http://www.canadashoppingcanadian.com

http://www.clickz.com

http://www.ducks.ca

http://www.canuckabroad.com

http://www.cndcountrygifts.com

http://www.canadacomputers.com

$\mathrm{http}: / / \mathrm{www}$.greatcanadianshopping.com

http://www.buyitcanada.com

http://www.walmart.com

http://www.costco.com

http://www.quixtar.com

http://www.feelbest.com

Germany:

http://www.shopping-online.de/

http://www.esprit-online-shop.com/

http://www.shopinfo.net/

http://www.amazon.de/exec/obidos/tg/browse/-

/301128/028-4151082-5062961?site-redirect=de

http://www.qvc.com/

http://www.pearl.de/

http://www.tiscali.de/main/main_center.html

http://www.yipi.de

http://de.yahoo.com/

http://www.eurocosm.com/

India:

http://shop.indiainfo.com

http://shopping.expomarkets.com

http://shopatchitralekha.tolshop.com/

http://www.ebay.in

http://www.captainartsandcrafts.com/enquiry.htm

http://www.indiangiftsportal.com/

http://www.fabmall.com/

http://sify.com/shopping/

https://www.sirindia.com/index.asp

http://shop.nirula.com/ 


\section{Israel:}

http://www.iguide.co.il

http://www.myisraelsource.com

http://www.internetstorelist.com

http://shop.katif.net

www.israelaustin.com

http://israel.zeezo.com

http://dmoz.org

http://www.allhlwines.com

http://www.livnot.com/shoppingcart/songbook.ht

$\mathrm{m}$

http://www.israzon.com

http://www.israel-shops.com

http://www.israelseed.com

http://judaism.about.com

http://1800sunstar.com

http://www.machers.com

http://www.jcolstore.com

http://abcnews.go.com

http://www.igourmet.com

http://www.cjp.org

http://www.flowers.co.il

\section{Italy:}

http://www.maptown.com/deskglobes.html

http://www.bigsoccershop.com

http://www.united-states-flag.com/italy3x $5 \mathrm{p} . \mathrm{html}$

http://www.bizrate.com/

http://bluespirit.vstore.ca/

http://news.earthweb.com/

http://www.italiamia.com/shopping.html

http://search.modaitalia.net/

http://www.elib.org/

http://www.ebay.it/

http://www.cao italy.com

http://www .NEXT - On-line Shopping

http://www .Pro Italia.com

http://www .Bella-Italia Online Shop

Japan:

http://www.outdoorjapan.com/marketplace/

http://www.planetliquor.com/japan/

http://www.yourdictionary.com

http://www.tnt-pc.com

http://www.cathaypacific.com

http://www.addall.com

http://www.sonore.com

http://www.japanvisitor.com/jc/links/japan-

shopping-links.html

http://toy.avantzone.com http://www.gridskipper.com

http://www.japan-guide.com

http://www.gojapan.about

http://www.jguide.stanford

http://www.findarticles

http://www.shopstashtea.com

http://www.theflyingpig.com

http://www.animecornerstore.com

http://www.export-japan.comuserintec.com

http://www.gaijinpont.com

http://www.faweb.netusaspashop.aspx

\section{Pakistan:}

http://www.worldofinternetcafes.de/Asia/Pakistan

http://fpcci.com.pk/chambers.asp

http://www.nowarzone.org/journal.aspx?ID=530

http://www.pocketmail.com/journal/

http://www.adbrite.com/mb/dir.php?page $=4 \& \mathrm{a}=2$ 0002.1.44012

http://www.adbrite.com/mb/dir.php?a=44012.1.2 0002\&page $=4$

http://www.tradekey.com/ks-PP-jumbo-bag/

http://hughw36.blogspot.com/2003_12_28_hugh

w36_archive.html

http://www.askwebhosting.com/whe/2004/web_h osting/Manhattan/

http://www.sunnisisters.com/sunnisister/?comme nts_popup $=758$

\section{Serbia:}

http://www.yu-

http://oglasi.com/racunari/messages/791.html

http://www.yu4you.com/

http://www.pcpress.co.yu/kupovina.asp

http://daliborpetkovic.tripod.com/

http://www.myshop.co.yu/

http://www.robnakuca.com/mailom.htm

http://www.videofilmovi.com/

http://www.karaoke.co.yu/narudzba.html

http://www.2net.co.yu/shop/

http://www.yusearch.com/start/index/

http:// www.zoopage.co.yu/

http://www3.ptt.yu/kategorije.php?section_1=3

http://www.list.co.yu/cms.php?a=Artikli\&as $=45$

$\& \mathrm{t}=72$

http://www.recepti.co.yu/recepti/sponzor.asp?IDs

ponzor

http://www.e-trgovina.co.yu/

http://www.pretraga.co.yu/direktorijumi/yuguide/i

ndex.php?k=4 
http://www.kupovinaonline.co.yu/content/view/2 $4 / 56 /$

http://http://www.cet.co.yu

http://http://www.aladin.co.yu

http://http://www.belgradeshop.com

http://www.multisoft.co.yu

http://www.maritrade.co.yu

http://www.fandjo.co.yu

http://www.auto-sport.co.yu

http://www.japan.shop.co.yu

http://www.zlatara.net

http://www.urbanshop.co.yu

http://www.neckermann.co.yu

http://www.kk-crvenazvezda.net-online-shop

http://www.cokolada.co.yu

http://www.encobook.co.yu

United Kingdom:

http://www.british-shopping.com

http://www.4ukshopping.co.uk

http://www.ishop.co.uk

http://www.marksandspencer.com

http://www.next.co.uk

http://www.shoppingtrolley.net

http://www.shopsafe.co.uk

http://www.ukoffer.com

http://www.uk-shoponline.co.uk

http://www.waitrose.com

http://www.kelkoo.co.uk/

http://www.tsoshop.co.uk/

http://www.play.com/

http://www.shopperuk.com/

http://www.argos.co.uk/static/Home.htm

http://www.gymuser.co.uk/shopping/shopping.ht

$\mathrm{m}$ http://www.virginmega.co.uk/

http://www.ebay.co.uk/

http://www.phones4u.co.uk/

http://www.onevillage.org

USA:

http://www.mysticalgift.com/xAuraSoma.aspx

http://www.usatf.org/store/

http://www.konicaminoltastore.com/

http://www.bella-usa.com/

http://www.ecost.com/ecost/ecsplash/default_new

.asp

http://disneyshopping.go.com/

http://esprit-usa.com/Merchant2/merchant.mvc

http://www.cduniverse.com

http://www.ica-

usa.org/Merchant $2 /$ merchant.mv?Screen=CTGY

$\&$ Store_Code $=$ ICA\&Category_Code $=$ courses

http://store.campfireusa.org/FAQ/Index.asp?IdS= $000 \mathrm{~A} 1 \mathrm{~F}$ -

FDC5380\&Reference $=$ GiftCertificates $\& \sim=$

http://www.compusa.com/

http://www.sony.com/

http://us.penguingroup.com/

http://www.fedstats.gov/

http://www.ikea.com/ms/en_US/

http://greenvilleonline.com/apps/pbcs.dll/frontpag e

http://www.nashbar.com/index.cfm

http://shopping.localstreets.com/xml/en/United_S tates/cate_840_0.html

http://store.palm.com/home/index.jsp

http://www.usatoday.com/tech/news/2005-11-27-

cyber-monday_x.htm 


\section{Biographies}

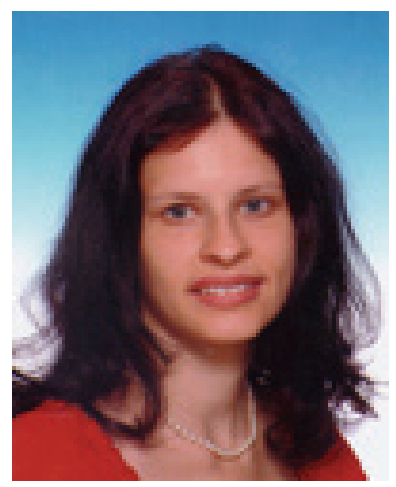

Tanja Krunić is a lecturer at the Advanced Technical School, Novi Sad, Serbia. She teaches courses in web design and Internet languages and tools. She holds an MSc in mathematics and is currently working towards her PhD in Numerical Analysis from the Faculty of Mathematics and Natural Sciences, Novi Sad. Her research interests include important issues like usability, accessibility, privacy, and security on the World Wide Web. She is a co-author of E-business and Information System Securing, Infotech 2005; How to Teach Mathematics in Special Circumstances, PRIM 2004; and the first author of E-commerce and User Privacy in Serbia and Montenegro, The 6-th International Conference on Electronic Commerce and Electronic Business, Palic 2006; Accessibility of E-commerce Websites in Serbia and Montenegro, The 6-th International Conference on Electronic Commerce and Electronic Business, Palic 2006, Web curriculum and Syllabus Based on Web Design Practice and Students' PpriorKknowledge, Insite, University of Salford, Greater Manchester, 2006.

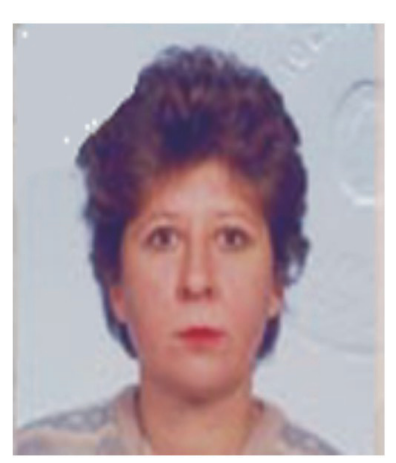

Ljiljana Ružić-Dimitrijević is a professor at the Advanced Technical School, Novi Sad, Serbia. She teaches courses in computers, computer graphics, and development of the Internet. She got her MSc degree in mathematics at the Center of Multidisciplinary Studies, Belgrade in 1991. Her field of expertise is computer graphics and web design. She is head of the graphic department at the Advanced Technical School. 